\title{
DYNAMIC NUMERICAL ANALYSIS OF STEEL FOOTBRIDGE
}

\author{
Maciej MAJOR ${ }^{1}$, Izabela MINDA ${ }^{1}$, Izabela MAJOR ${ }^{1,{ }^{*}}$ \\ ${ }^{1}$ Czestochowa University of Technology, Faculty of Civil Engineering, ul. Akademicka 3, 42-200 \\ Częstochowa, Poland. \\ corresponding author: imajor@bud.pcz.czest.pl
}

\section{Abstract}

The study presents a numerical analysis of the arched footbridge designed in two variants, made of steel and aluminium. The first part presents the criteria for evaluation of the comfort of using the footbridges. The study examined the footbridge with arched design with span in the axis of $24 \mathrm{~m}$ and width of $1.4 \mathrm{~m}$. Arch geometry was made as a part of the circle with radius of $r=20 \mathrm{~m}$ cut off with a chord with length equal to the calculation length of the girders. The model of the analysed footbridge was subjected to the dynamic effect of wind and the pedestrian traffic with variable flexibility. The analyses used Robot Structural Analysis software.
\end{abstract}

\section{Keywords:}

Footbridge;

Dynamic analysis;

Vibrations.

\section{Introduction}

Nowadays, footbridges are designed as structures with increasingly high design span [1]. Therefore, the necessary component of their analyses is to take into account the dynamic susceptibility of the structure to wind gusts and dynamic effects of the pedestrian traffic. The dynamic analysis that included determination of the natural vibration frequencies and their modes and the risk of resonance vibrations [2] is especially important for the design of light and slender structures, with low weight and insignificant stiffness. The vibrations that occur in the case of the footbridge, leading to the discomfort perceived by pedestrian, are often revealed after the structure is used in practice.

Selection of appropriate type of construction depends on planned span dimension, its function (type of obstacles, the form of utilization, location etc.), time of realization, project economics, etc. There are many researches of bridge structures (also existing) which allows to designate a competent solutions [3, 4].

This study presents a dynamic analysis of two models of an arched footbridge designed as steel and aluminium structures, respectively. The model of the footbridge was subjected to the dynamic effect of wind and the pedestrian traffic with variable flexibility. The analysis was preceded by the evaluation using the Autodesk Robot Structural Analysis software, which is dedicated to engineering applications (see also [5, 6]).

\section{Criteria for evaluation of the comfort of using footbridges}

The diagram presented in Fig. 1 presents the procedure of the dynamic analysis of footbridges. The basic criterion for the analysis is to determine the natural vibration frequencies and their modes for the footbridge and the analysis of the critical range of frequencies of dynamic effects.

If the parameters exceed the permissible values and there is a risk of resonance vibrations, one should determine the level of vibration damping and levels of accelerations of vertical and horizontal vibration that translate into the level of comfort during using of the footbridge.

Table 1 [2] presents typical step frequencies for individual phases of human gait.

The research in such laboratory centre was conducted for five years and its results were continuously published. The laboratory centre also was used like an illustration of Department research for educational purposes. 
Table 1: The frequency of pedestrian traffic $\mathrm{Hz}$ [2].

\begin{tabular}{|l|c|c|c|c|}
\hline Type of traffic & Total range & Slow tempo & Normal tempo & Fast tempo \\
\hline Going & $1.4-2.4$ & $1.4-1.7$ & $1.7-2.2$ & $2.2-2.4$ \\
\hline Running & $1.9-3.3$ & $1.9-2.2$ & $2.2-2.7$ & $2.7-3.3$ \\
\hline Jumping & $1.3-3.4$ & $1.3-1.9$ & $1.9-3.0$ & $3.0-3.4$ \\
\hline
\end{tabular}

The greatest values of the dynamic effect are generated by running and jumping of a pedestrian. The unfavourable resonance can be caused by using the structure in a manner which is not permissible for such structures, e.g. marching in step through the footbridge. The properly designed bridge structures are those with natural vibration greater or equal to $5 \mathrm{~Hz}$.

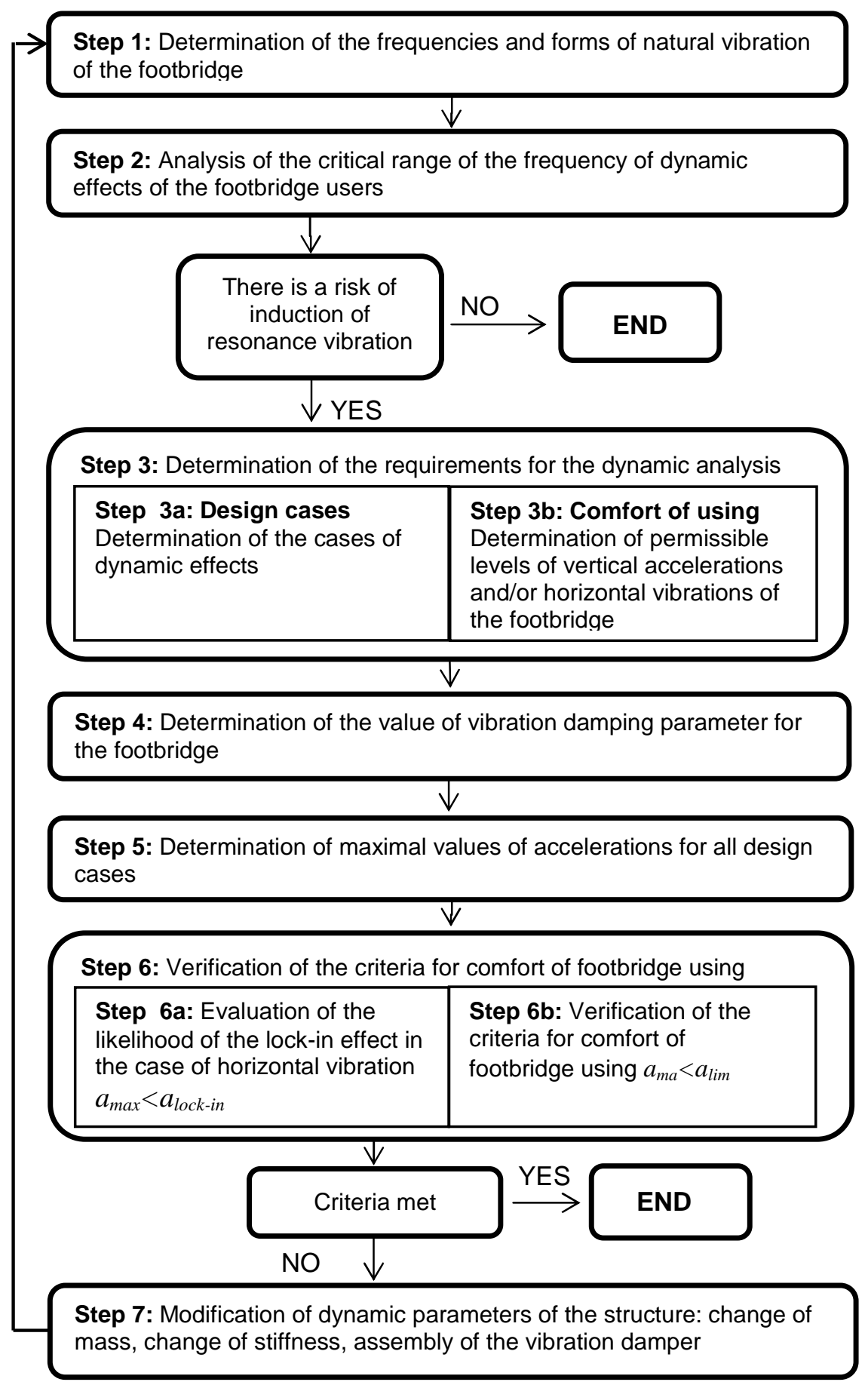

Fig. 1: Diagram of the procedure of the dynamic analysis of footbridge [2]. 
Another important aspect is assessment of the comfort of using the design. This is determined based on the levels of acceleration of vibration and comparing them with the permissible values defined in [2]. Ensuring first class of comfort guarantees that the pedestrians moving on the footbridge do not feel oscillations. Class 2 causes the vibration which is slightly discernible by pedestrians, whereas class 3 means substantially felt vibration, but permissible under condition of rare occurrence. Class 4 disqualifies the object from being used since excessive oscillations make it difficult to cross the footbridge and are unacceptable for the structure users. The values of vibration accelerations are contained in Table 2.

Mass dampers should be used in the case of excessive vibration amplitudes to reduce the vibrations. The reduction can be also achieved by changing the weight or stiffness of the bridge span subjected to the excessive vibration.

Table 2: Values of vibration acceleration $\left[\mathrm{m} / \mathrm{s}^{2}\right]$.

\begin{tabular}{|c|c|c|c|}
\hline \multirow{2}{*}{ Comfort class } & \multirow{2}{*}{ Comfort rating } & \multicolumn{2}{|c|}{ Acceleration of vibrations $\boldsymbol{a}_{\mathbf{m a x}}\left[\mathrm{m} / \mathbf{s}^{2}\right]$} \\
\cline { 3 - 4 } & & Vertical & Horizontal \\
\hline Class 1 & Maximum comfort & $0.0-0.5$ & $0.5-0.15$ \\
\hline Class 2 & Medium comfort & $0.5-1.0$ & $0.15-0.3$ \\
\hline Class 3 & Minimal comfort & $1.0-2.5$ & $0.3-0.8$ \\
\hline Class 4 & No comfort & $>2.5$ & $>0.8$ \\
\hline
\end{tabular}

\section{Model of construction}

The dynamic analysis concerned the supported footbridge (Fig. 2) made in the first variant from S355 steel, whereas in the second - from aluminium. The object is adapted for an unlimited pedestrian traffic in two directions but it does not accept bicycle traffic and traffic of emergency vehicles.

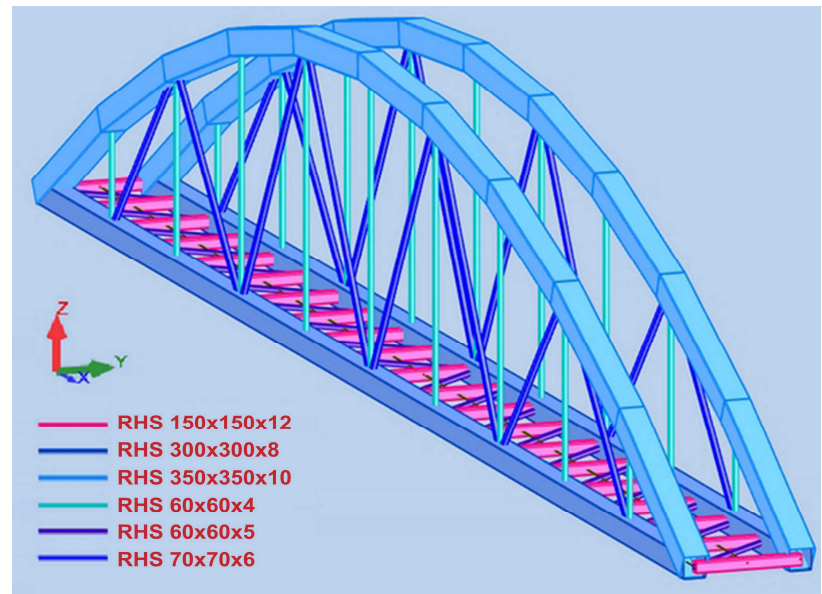

Fig. 2: The model of the footbridge design was generated in the Robot Structural Analysis software.

In the third and fourth node (see Fig. 3), two supports were used to block the movement in $X, Y$ and $Z$ directions for the adopted coordinate system. Two other supports allow for the displacement in $X$ axis (node 2) and $Y$ axis (node 1) while removing two other degrees of freedom connected with the movement.

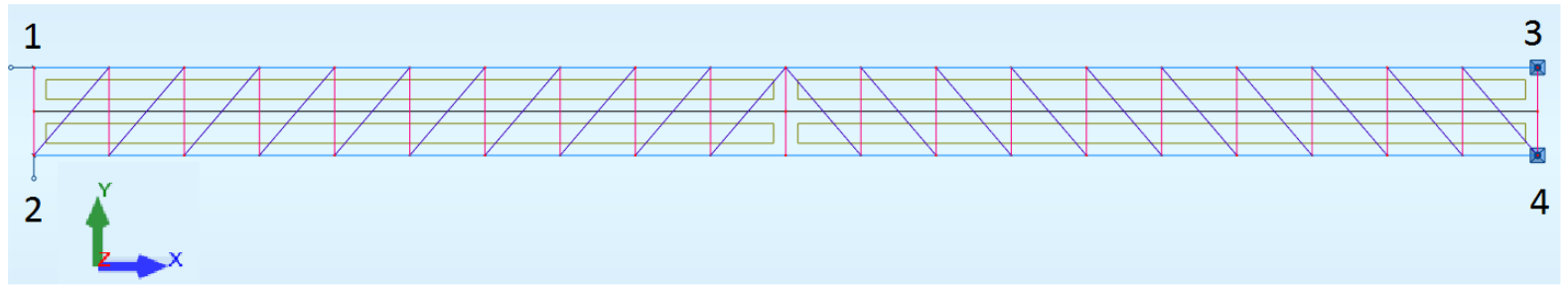

Fig. 3: Boundary conditions. 
The object analysed is a footbridge with arched design with span in the axis of $24 \mathrm{~m}$ and width of $1.4 \mathrm{~m}$. Arch geometry was made as a section of the circle with radius of $r=20 \mathrm{~m}$ cut off with a chord with length equal to the calculation length of the girders. In order to provide additional stiffness, the design was made rigid in $\mathrm{YX}$ and $\mathrm{ZX}$ planes. The dimensions of the footbridge are presented in Figs. 4 and 5. Table 3 contains types of sections used for individual components of the structure.

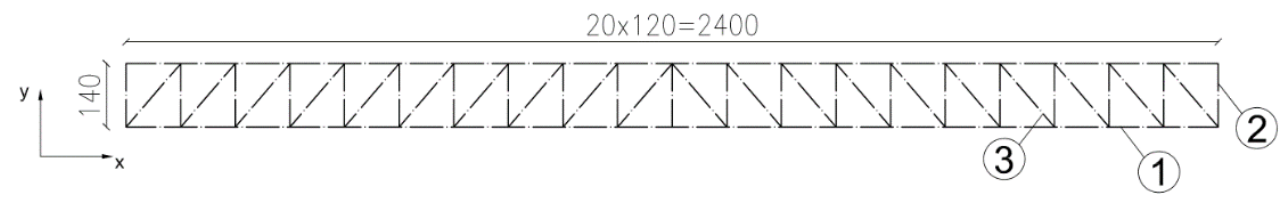

Fig. 4: The computational dimensions of the footbridge in the YX plane. 1, 2, 3 according to Table 3.

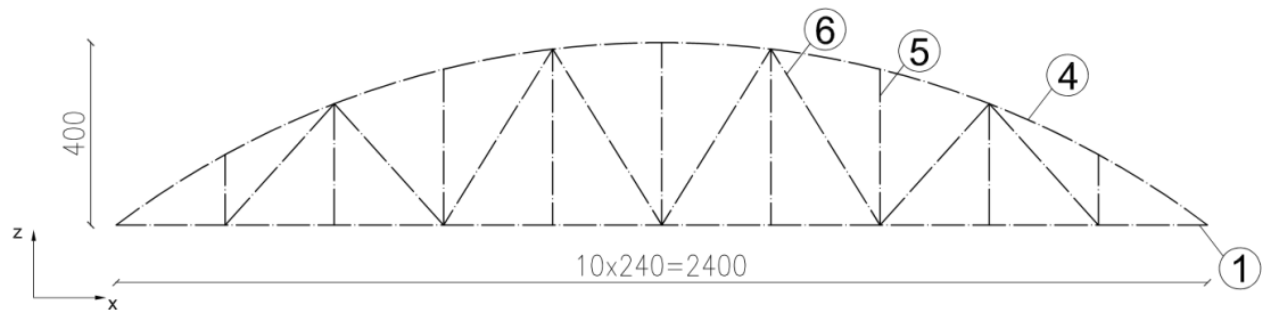

Fig. 5: The computational dimensions of the footbridge in the ZX plane. 4, 5, 6 according to Table 3.

Table 3: List of sections used in the designed footbridge construction.

\begin{tabular}{|c|c|c|}
\hline $\begin{array}{c}\text { Profile } \\
\text { (Figs. 4 and 5) }\end{array}$ & Name of the element & Type of the profile \\
\hline 1 & Girder & RHS $300 \times 300 \times 12$ \\
\hline 2 & Cross-bar & RHS $150 \times 150 \times 12$ \\
\hline 3 & Bracing & RHS $60 \times 60 \times 5$ \\
\hline 4 & Arch & RHS 350 $550 \times 10$ \\
\hline 5 & Post & RHS $60 \times 60 \times 4$ \\
\hline 6 & Bracing & RHS $70 \times 70 \times 6$ \\
\hline
\end{tabular}

\section{Dynamic analysis}

\subsection{Footfall harmonic analysis}

The Footfall harmonic analysis concerned two arched models of the footbridge with the same geometrical parameters. The first model was made of S355 steel, whereas the other is made of aluminium. This analysis consists in determination of the effect of human gait on the structure vibration [7].

Harmonic load was applied to all nodes that belonged to the panels of the footbridge surface. Three cases of pedestrian movement frequency were analysed. In the first case, the frequency was applied in the range of 1.4 to $2.4 \mathrm{~Hz}$, denoting normal gait of movement participants on the footbridge. Another range is $1.9-3.3 \mathrm{~Hz}$, which occurs when pedestrians are running, and the last range is typical of jumping pedestrians, reaching 1.3 to $3.4 \mathrm{~Hz}$. The pedestrian mass was assumed as $90 \mathrm{~kg}$. Constant dumping was 0.05 .

The full method of exciting vibration was used to evaluate the effects of the analysis that verifies the influence of the force applied to a specific node and its response in any node [7]. According to the range of acceptable frequencies, the SCI P354 analysis was chosen $(1.2-4.5 \mathrm{~Hz})$.

The modes of vibration presented in the Figs. 6 to 9 adopt the analogous shape regardless of the material used and the frequencies of the pedestrian traffic. 


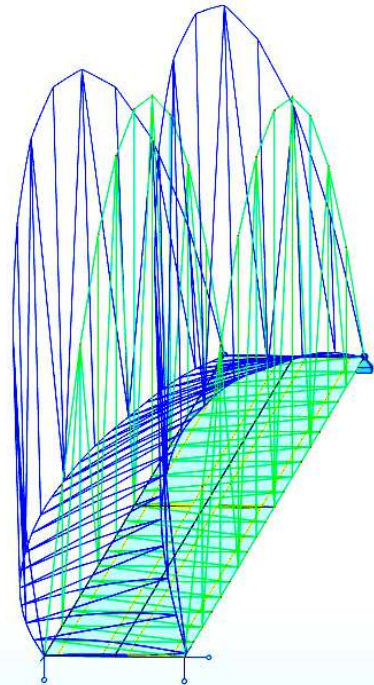

Fig. 6: The first mode of footbridge vibrations.

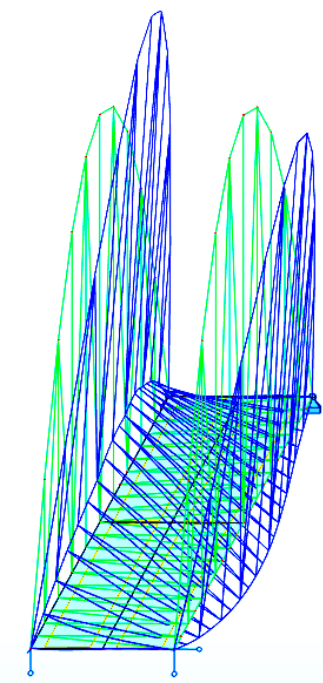

Fig. 7: The second mode of footbridge vibrations.

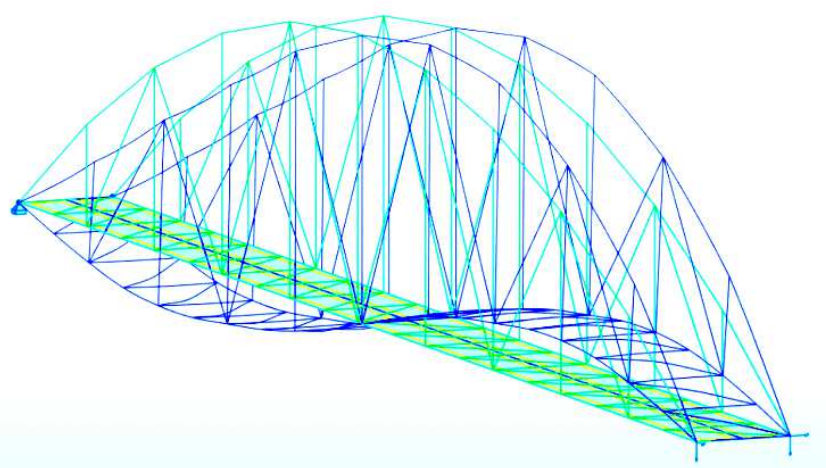

Fig. 8: The third mode of footbridge vibrations.

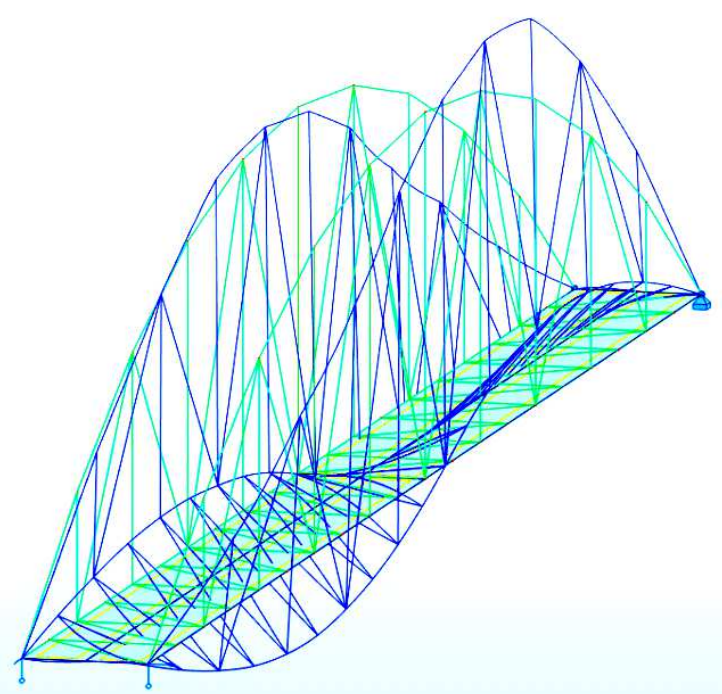

Fig. 9: The fourth mode of footbridge vibrations.

Maximal values of vertical acceleration of vibration $a\left[\mathrm{~m} / \mathrm{s}^{2}\right]$ and response coefficient $R_{\mathrm{f}}$ (that determines how many times the calculated vibrations exceed acceptable values perceived by human) [7] obtained during Footfall analysis were contained in Table 4. 
Table 4: Maximal values: $a$ - vertical acceleration of vibration $\left[\mathrm{m} / \mathrm{s}^{2}\right]$ and $R_{\mathrm{f}}-$ response coefficient obtained from Footfall analysis.

\begin{tabular}{|c|c|c|c|}
\hline \multicolumn{2}{|c|}{ Range of forced frequency } & Steel & Aluminium \\
\hline Going \\
$1.4-2.4[\mathrm{~Hz}]$ & $a$ Total $\left[\mathrm{m} / \mathrm{s}^{2}\right]$ & 0.004 & 0.012 \\
\cline { 2 - 4 } & $R_{\mathrm{f}}$ & 0.840 & 2.350 \\
\hline Running & $a$ Total $\left[\mathrm{m} / \mathrm{s}^{2}\right]$ & 0.009 & 0.025 \\
\cline { 2 - 4 } $1.9-3.3[\mathrm{~Hz}]$ & $R_{\mathrm{f}}$ & 1.760 & 4.940 \\
\hline Jumping & $a$ Total $\left[\mathrm{m} / \mathrm{s}^{2}\right]$ & 0.009 & 0.027 \\
\cline { 2 - 4 } $1.3-3.4[\mathrm{~Hz}]$ & $R_{\mathrm{f}}$ & 1.890 & 5.31 \\
\hline
\end{tabular}

The response coefficients for the analysis SCl P354 are calculated based on the mean acceleration $a_{r m s}$ (see Fig. 10) weighted by the frequency $a_{w, r m s}[8]$ :

$R_{f}=\frac{a_{r m s}}{a_{\mathrm{R}=1}}$

where:

$a_{\mathrm{R}=1}$ - base acceleration $a_{\mathrm{R}=1}\left[\mathrm{~m} / \mathrm{s}^{2}\right]$ for vertical vibrations with regards to the $Z$ axis according to BS 6472 and ISO 10137 is $a_{\mathrm{R}=1}=5 \times 10^{-3}[7]$

$a_{r m s}=\sqrt{\frac{1}{T} \int_{0}^{T} a(t)^{2} d t}$

where:

$T$ - period of vibration (period of time involving at least one entire acceleration cycle, value recommended by ISO 2631-1:1997, $T=1 \mathrm{~s}$ ) [8],

$a(t)$ - acceleration function,

$t$ - time.

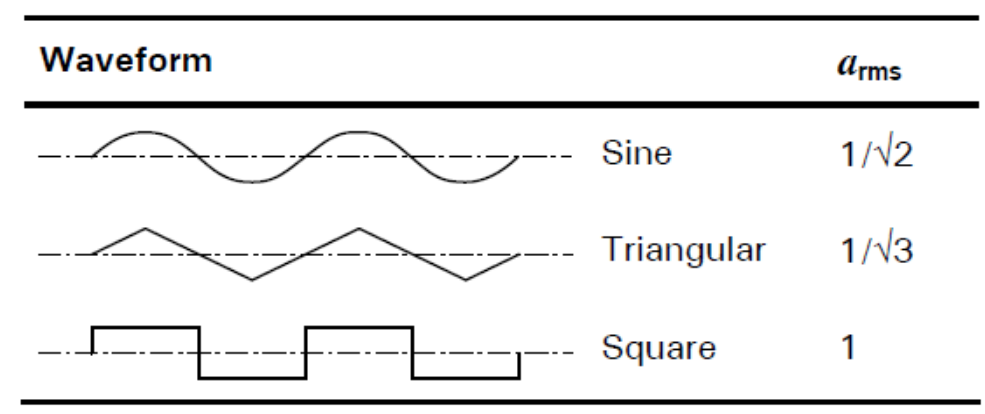

Fig. 10: Values of accelerations $a_{r m s}$ for different waveforms [8].

According to Table 1, which describes class of comfort of using the structure, the values of vibration acceleration meet acceptable values of class 1 (that ensures maximal comfort for pedestrians) for both steel and aluminium structures.

Footfall analysis showed that the condition of imperceptibility of vibration by pedestrians was met only in the case of the group of people with frequency $1.4-2.4 \mathrm{~Hz}$ crossing the whole steel footbridge. With pedestrians' running or jumping, the vibrations are felt by users across all over the surface of the footbridge, which is permissible only if this case does not occur often. If this situation is likely to occur, the dampers should be used to reduce vibration.

In the case of the aluminium footbridge, the permissible level of perception of oscillation by humans was exceeded by 5 times. The use of such a structure causes a pedestrian discomfort and can lead to health or even life risks due to quick destruction of the structure. 
Table 5: The values of the vibration frequencies for the four modes of vibrations.

\begin{tabular}{|c|c|c|c|}
\hline Mode of vibrations & Frequency [Hz] & Period [s] & Pulsation [1/s] \\
\hline 1 & 20.43 & 0.05 & 128.38 \\
\hline 2 & 25.38 & 0.04 & 159.45 \\
\hline 3 & 28.09 & 0.04 & 176.48 \\
\hline 4 & 34.37 & 0.03 & 215.95 \\
\hline
\end{tabular}

Table 5 illustrates the values of frequency, period and pulsation caused by a dynamic effect of the pedestrian traffic. The results of the analysis were the same for both models. According to [7], there is no risk of resonance vibrations between excitations if the basic values of natural vibrations exceed from 8 to $10 \mathrm{~Hz}$. Therefore, according to Table 5, the lowest value of natural vibration occurring in the first mode of vibration excludes the risk of resonance through deliberate actions taken by a group of pedestrians. This also points to the sufficient rigidity of the structure.

\subsection{Modal analysis}

The modal analysis was performed for a dynamic load with wind from the left or right side, acting on vertical load-bearing components of the structure and the arch. Wind effect was calculated according to [9] for the 1st wind zone, with additional consideration for the aerodynamic resistance coefficient for trussed structures. The load was applied as a rod mass of $0.91 \mathrm{kN} / \mathrm{m}$. Figs. $11-14$ shows a graphical representation of the first four modes of vibration. Table 6 contains values of natural vibration frequencies for consecutive modes of vibration.

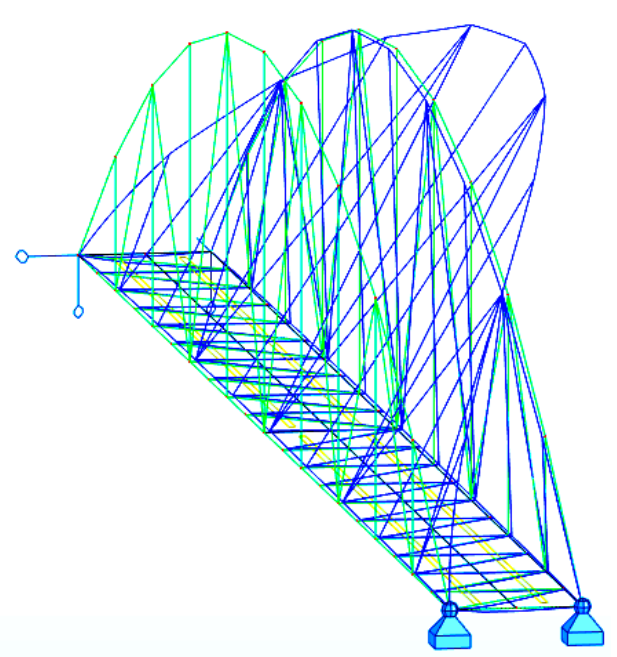

Fig. 11: The first mode of footbridge vibrations.

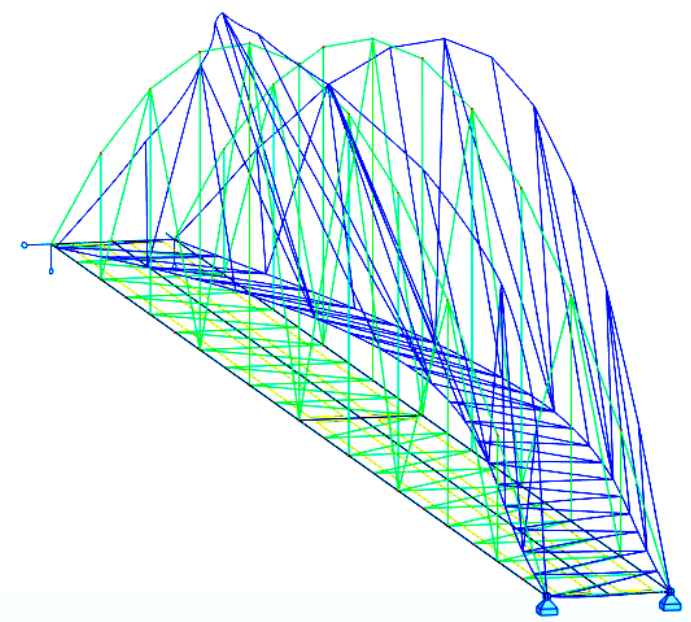

Fig. 13: The third mode of footbridge vibration.

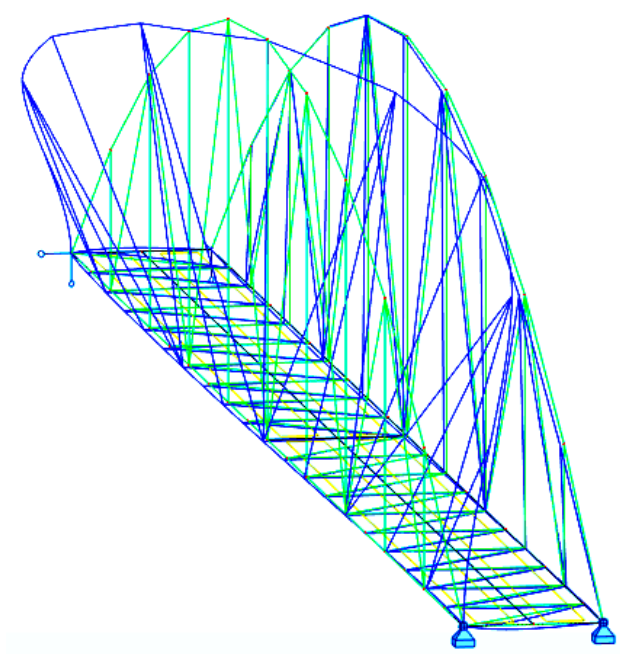

Fig. 12: The second mode of footbridge vibrations.

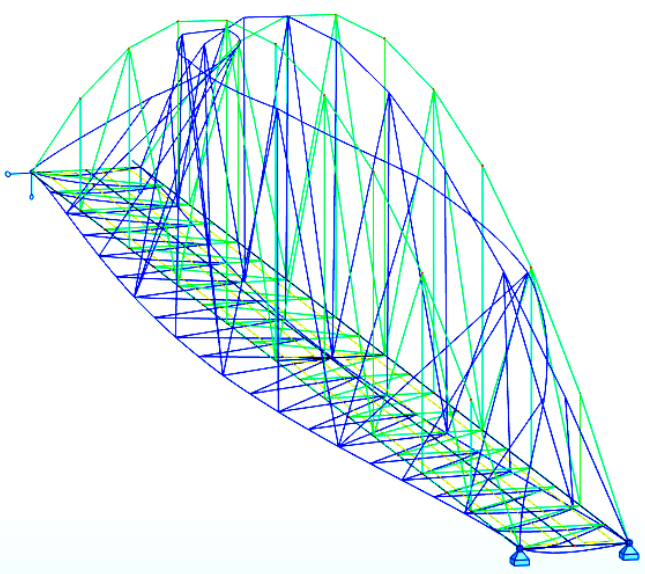

Fig. 14: The fourth mode of footbridge vibration. 
Table 6: The values of the vibration eigenfrequencies for next modes of vibrations.

\begin{tabular}{|c|c|c|c|c|c|c|}
\hline \multirow{2}{*}{$\begin{array}{c}\text { Mode of } \\
\text { vibrations }\end{array}$} & \multicolumn{2}{|c|}{ Frequency [Hz] } & \multicolumn{2}{c|}{ Period [s] } & \multicolumn{2}{c|}{ Pulsation [1/s] } \\
\cline { 2 - 7 } & Steel & Aluminium & Steel & Aluminium & Steel & Aluminium \\
\hline 1 & 1.92 & 0.11 & 0.52 & 8.72 & 12.08 & 0.72 \\
\hline 2 & 6.02 & 0.36 & 0.17 & 2.78 & 37.82 & 2.26 \\
\hline 3 & 11.27 & 0.67 & 0.09 & 1.48 & 70.84 & 4.23 \\
\hline 4 & 12.66 & 0.76 & 0.08 & 1.32 & 79.56 & 4.75 \\
\hline 5 & 17.93 & 1.07 & 0.06 & 0.93 & 112.67 & 6.73 \\
\hline 6 & 20.33 & 1.21 & 0.05 & 0.82 & 127.74 & 7.63 \\
\hline 7 & 24.17 & 1.44 & 0.04 & 0.69 & 151.87 & 9.06 \\
\hline 8 & 32.09 & 1.92 & 0.03 & 0.52 & 201.63 & 12.05 \\
\hline 9 & 36.97 & 2.21 & 0.03 & 0.45 & 232.30 & 12.87 \\
\hline 10 & 38.85 & 2.32 & 0.03 & 0.43 & 244.10 & 14.58 \\
\hline
\end{tabular}

Eigenvalues and eigenmodes are obtained from the following formula [7]:

$\left(K-\omega_{1}^{2} M\right) U_{i}=0$,

where:

$K$ - stiffness matrix of the structure,

$M$ - mass matrix of the structure,

$\omega_{i}-$ natural pulsation (natural circular frequency) of mode " $"$ ",

$U_{i}$ - eigenmode vector of mode " $i "$.

Modal analysis revealed the incorrect design of the footbridge in the case of aluminium structure. With the dynamic wind effect, the object reaches values of natural vibrations which are substantially lower than the recommended acceptable value for this type of structures, which is $2.5 \mathrm{~Hz}$ for horizontal wind impact.

Furthermore, the value of the vibration frequency of the first mode for the steel footbridge is too low and similar to the frequency of the pedestrian traffic, which might lead to an unfavourable resonance effect. However, this does not exclude the use of the structure if the special components are used to reduce the vibration level.

\section{Conclusions}

This study analysed the dynamic effect of wind and pedestrian stream on the structure of the footbridge made from steel and aluminium. The Footfall analysis include the extreme case of the dynamic load, connected with presence of the group of people on the whole surface of the footbridge in three cases moving frequency: for walking, running and jumping. Maximal values of vibration acceleration was obtained for the range of forced frequencies of $1.3-3.4 \mathrm{~Hz}$ (jump) with $0.009 \mathrm{~m} / \mathrm{s}^{2}$ for the steel structure, which can be regarded as permissible in the case of rare occurrence. Furthermore, if the footbridge is made from aluminium, the value of vibration accelerations exceed the comfort value by over 5 times, which disqualifies the opportunities for the use of the object due to the difficulties with pedestrian traffic. Analysis of the steel structure showed that proper use of the structure (walking) ensures maximal comfort even in the case of a large group of pedestrians.

Modal analysis connected with the dynamic wind effect demonstrated inadequate design of the aluminium structure since the value of vibration frequency in the first ten of the analysed modes are substantially lower than $5 \mathrm{~Hz}$ that ensures the correctness of the structure and comfort of the object use by pedestrians.

In conclusion, the analyses showed that the structure made of steel is a substantially better constructional solution since it meets the requirements of comfort of using by pedestrians and there is only a minimal risk of the resonance effect. Therefore, the likelihood of destruction of the object as a result of the dynamic effects is also insignificant. 


\section{References}

[1] BARCIK, W. - BILISZCZUK, J. - MACHELSKI, C.: Projektowanie stalowych kładek dla pieszych Design of steel footbridges, Dolnośląskie Wydawnictwo Edukacyjne, Katowice 2007, ISBN: 9788371251597 (In Polish).

[2] PAŃTAK, M.: Analizy dynamiczne w projektowaniu kładek dla pieszych, Dynamic analysis in the design of footbridges, Przegląd budowlany 6/2016, Wydział Inżynierii Lądowej Politechniki Krakowskiej, pp. 78 - 82 (In Polish).

[3] VIČAN, J. - GOCAL, J. - ODROBINAK, J. - MORAVCIK, M. - KOTEŠ, P.: Determination of Railway Bridges Loading Capacity, Procedia Engineering, Vol. 111, pp. 839 - 844, doi:10.1016/j.proeng.2015.07.155, 2015.

[4] KREJSA, M. - TOMICA, V.: Determination of inspections of structures subject to fatigue, Transactions of the VŠB - Technical University of Ostrava, Civil Engineering Series. Vol. 11, Issue 1, pp. 1 - 9, ISSN (Online) 1804-4824, ISSN (Print) 1213-1962, DOI: https://doi.org/ 10.2478/v10160-011-0007-x, June 2011.

[5] MAJOR, M. - KULIŃSKI, K.: Comparative numerical analysis of advertising board tower using ADINA and Autodesk ROBOT Structural Analysis, Transactions of the VŠB - Technical University of Ostrava, Civil Engineering Series. Vol. 15, Issue 2, ISSN (Online) pp.1804 - 4824, DOI: https://doi.org/10.1515/tvsb-2015-0015, January 2016.

[6] MAJOR, M. - MAJOR, I.: Computer Aided Design - Comparative Analysis of Widely Available Software with Analytical Method, Transactions of the VŠB - Technical University of Ostrava, Civil Engineering Series, Vol. 14, Issue 2, pp. 79 - 84, ISSN (Online) 1804-4824, DOI: https://doi.org/ 10.2478/tvsb-2014-0023, December 2014.

[7] Autodesk ${ }^{\circledR}$ Robot ${ }^{\mathrm{TM}}$ Structural Analysis Professional, Podręcznik użytkownika, 2014, http://docs.autodesk.com/RSAPRO/2014/PLK/index.html?url=filesROBOT (In Polish).

[8] SCI P354: Design of Floors for Vibration: A New Approach The Steel Construction Institute (2007 Edition).

[9] PN-EN 1991-1-4:2008, Eurocode 1: Actions on structures, Part 1-4: General actions - wind actions, PKN, Warszawa, 2008, (In Polish). 